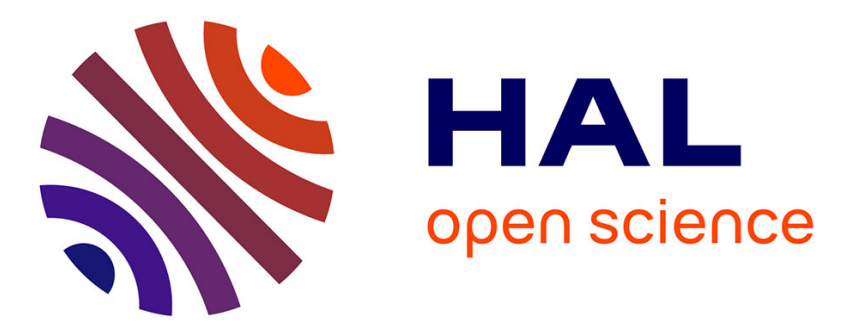

\title{
The shallow of your smile: the ethics of expressive vocal deep-fakes
}

\author{
Nadia Guerouaou, Guillaume Vaiva, Jean-Julien Aucouturier
}

\section{To cite this version:}

Nadia Guerouaou, Guillaume Vaiva, Jean-Julien Aucouturier. The shallow of your smile: the ethics of expressive vocal deep-fakes. Philosophical Transactions of the Royal Society B: Biological Sciences, 2021, 377 (20210083), pp.1 - 5. 10.1098/rstb.2021.0083 . hal-03455023

\section{HAL Id: hal-03455023 https://hal.science/hal-03455023}

Submitted on 29 Nov 2021

HAL is a multi-disciplinary open access archive for the deposit and dissemination of scientific research documents, whether they are published or not. The documents may come from teaching and research institutions in France or abroad, or from public or private research centers.
L'archive ouverte pluridisciplinaire HAL, est destinée au dépôt et à la diffusion de documents scientifiques de niveau recherche, publiés ou non, émanant des établissements d'enseignement et de recherche français ou étrangers, des laboratoires publics ou privés. 


\section{PHILOSOPHICAL TRANSACTIONS B}

royalsocietypublishing.org/journal/rstb

\section{Research}
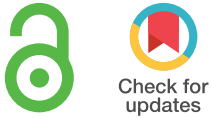

Cite this article: Guerouaou N, Vaiva G, Aucouturier J-J. 2021 The shallow of your smile: the ethics of expressive vocal deep-fakes. Phil. Trans. R. Soc. B 20210083.

https://doi.org/10.1098/rstb.2021.0083

Accepted: 28 July 2021

One contribution of 12 to a theme issue 'Voice modulation: from origin and mechanism to social impact (Part II)'.

\section{Subject Areas:}

cognition, behaviour

\section{Keywords:}

voice transformation, ethics, deep-fake, moral psychology, emotions

\section{Author for correspondence:}

Nadia Guerouaou

e-mail: nadia.guerouaou@chru-lille.fr

Electronic supplementary material is available online at rs.figshare.com.

\section{THE ROYAL SOCIETY}

\section{The shallow of your smile: the ethics of expressive vocal deep-fakes}

\author{
Nadia Guerouaou ${ }^{1,2}$, Guillaume Vaiva ${ }^{2}$ and Jean-Julien Aucouturier ${ }^{3,4}$ \\ ${ }^{1}$ Science and Technology of Music and Sound, IRCAM/CNRS/Sorbonne Université, Paris, France \\ ${ }^{2}$ Lille Neuroscience and Cognition Center (LiNC), Team PSY, INSERM U-1172/CHRU Lille, France \\ ${ }^{3}$ FEMTO-ST, UBFC/CNRS, Besançon, France \\ ${ }^{4}$ Alta Voce SAS, Houilles, France \\ ${ }^{4}$ Centre National de Ressource et Résilience (CN2R Lille Paris), Lille, France
}

\section{(iD) NG, 0000-0003-2319-623X}

Rapid technological advances in artificial intelligence are creating opportunities for real-time algorithmic modulations of a person's facial and vocal expressions, or 'deep-fakes'. These developments raises unprecedented societal and ethical questions which, despite much recent public awareness, are still poorly understood from the point of view of moral psychology. We report here on an experimental ethics study conducted on a sample of $N=303$ participants (predominantly young, western and educated), who evaluated the acceptability of vignettes describing potential applications of expressive voice transformation technology. We found that vocal deepfakes were generally well accepted in the population, notably in a therapeutic context and for emotions judged otherwise difficult to control, and surprisingly, even if the user lies to their interlocutors about using them. Unlike other emerging technologies like autonomous vehicles, there was no evidence of social dilemma in which one would e.g. accept for others what they resent for themselves. The only real obstacle to the massive deployment of vocal deep-fakes appears to be situations where they are applied to a speaker without their knowing, but even the acceptability of such situations was modulated by individual differences in moral values and attitude towards science-fiction.

This article is part of the theme issue 'Voice modulation: from origin and mechanism to social impact (Part II)'.

\section{Introduction}

The human facial and vocal expressions have evolved as signals to inform and manipulate others [1,2]. By continuously modulating our facial muscles and the phonatory and articulatory structures of our vocal apparatus, we provide a rich, flexible non-verbal back-channel to our daily conversations, communicating our emotional states such as joy or surprise [3,4], our social intents such as warmth or dominance $[5,6]$ or our epistemic attitudes, such as certainty or doubt $[7,8]$.

While our facial and vocal expressions were shaped by a long and delicate interplay of biological and cultural evolution [9,10], spectacular technological advances occurring in the past few years may soon dramatically alter how we use and experience these behaviours in daily life. Recent progress in signal processing have indeed made possible the real-time manipulation of e.g. facial expressions such as smiles [11] and vocal expressive cues such as pitch [12] or timbre [11]. Perhaps even more radically, recent advances in deep neural network architectures have provided a flexible way to learn and generate mappings (or 'deep-fakes' [13]) between pairs of stimuli, and opened possibilities to parametrically manipulate individual facial actions [14] (figure 1b) or convert one voice into several emotional variants [15]. In just a few years, combined with the unprecedented adoption of remote communication software such as video conferencing and virtual meetings, we have come to a situation where it is

C 2021 The Authors. Published by the Royal Society under the terms of the Creative Commons Attribution License http://creativecommons.org/licenses/by/4.0/, which permits unrestricted use, provided the original author and source are credited. 


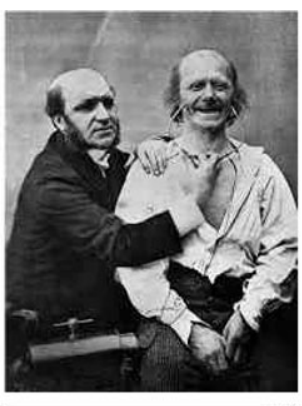

1872

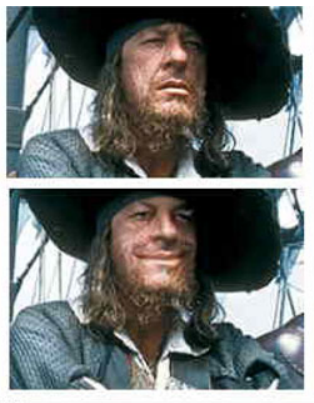

2018

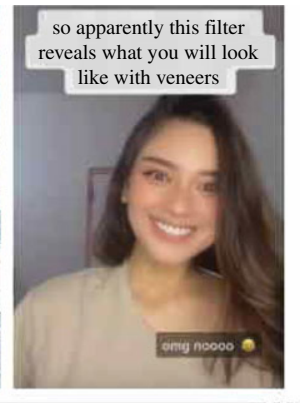

2020

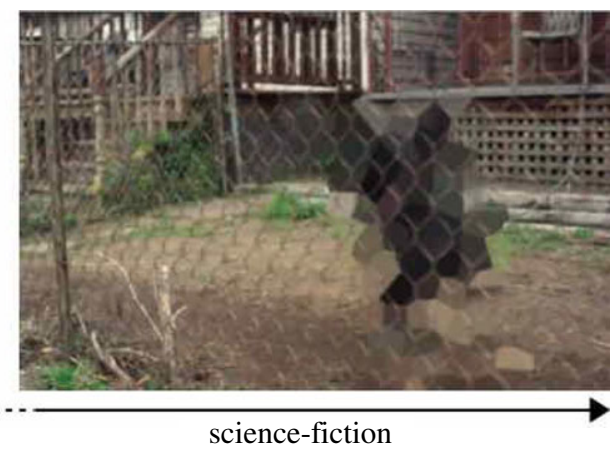

science-fiction

Figure 1. From Darwin to deep-learning: rapid technological advances in artificial intelligence create opportunities for real-time algorithmic modulations of facial and vocal expressions, which raises unprecedented societal and ethical questions. From left to right: (a) Original studies of human facial expressions employed electric stimulation to induce muscle contraction (Guillaume Duchenne de Boulogne, reproduced in [1]); (b) Manipulation of individual action units in still photographs using Generative Adversarial Networks (GANimation [14]); (c) Real-time smile filters in commercial video sharing plateforms (Tiktok, ByteDance Ltd., Beijing, (hina); (d) Still from the Arkangel episode of dystopian science fiction television series Black Mirror (Endemol Shine UK Ltd., 2017) in which parents equip their children with anti-violence visual filters via a brain implant. Here, the device visually filters out a dog aggressively barking at the child, directly in the child's mind. (Online version in colour.)

difficult to trust whether the smiles, laughs and frowns of our conversation partners are genuine or algorithmically modulated (figure 1c).

The goal of this paper is to initiate the data-driven study of expressive deep-fakes ethics (specifically here, vocal deepfakes) and, inspired by the methodology of 'experimental ethics' [16], to quantify societal expectations about the principles that should guide their deployment.

The realistic, artificial manipulation of expressive behaviour raises unprecedented societal and ethical questions. First, it raises concerns about truthfulness. Because expressive behaviours are often thought to provide genuine cues about the sender's emotional states [17], the ability to arbitrarily manipulate these displays opens avenues for deception: one may use, e.g. a facial filter to fake a smile despite having no intent to affiliate, or a voice transformation to appear more certain than one really is. Second, they raise concerns about fairness. Expressive behaviours in verbal interactions strongly influence subsequent behaviours. It is already known that vendors displaying positive, authentic expressions while interacting with customers sell more mobile phones [18], or that negociators faking anger in commercial discussions obtain better prices [19]. The algorithmic manipulation of expressions designed for such situations may coerce people into making unwarranted or unfair decisions. Third, they raise concerns about autonomy. Non-verbal influences on behaviour are often non-conscious: in a study with voice transformation, mock patients calling 911 medical triage with a more dominant voice obtained more urgent medical responses from doctors but doctors did not attribute the cause of their behaviour to the patient's voice; rather, they wrongly attributed it to more urgent medical situations [20] (figure 2, bottom). Technologies able to trigger such unconscious reactions are therefore intrinsically manipulative, as people may not be able to identify the transformation as the cause for their subsequent behaviour. Finally, they also raise concerns about transparency, as their deployment in virtual conversations lends itself to situations where a speaker doesn't know how their interlocutor is hearing or seeing them, i.e. whether a transformation of their own voice or face is applied without their knowing.

However, none of these deontological concerns warrants a straightforward moral objection to the deployment of expressive transformation technologies, because each of them also create opportunities for highly desirable situations. First, the fact that e.g. a smiling voice transformation can be used to appear happier than one really is becomes highly desirable in the case of patients who cannot easily express emotions (e.g. Amyotrophic lateral sclerosis patients who rely on assistive voice technology for communication, [22]). Second, the fact that voice or face transformations can coerce observers into subsequent actions can be desirable in interventions where people are nudged into positive behaviour [23], for instance reducing aggressive behaviour in call-centre conversations by transforming the operator's fatigued voice [24], or applying a gender voice transformation on an online hiring platform to alleviate gender biases [21] (figure 2, top). Third, the fact that expressive transformations can be processed unconsciously may be desirable in situations where this increases their effectiveness, as seen e.g. in emotional vocal feedback [25].

Societal expectations in such situations are non-trivial and important to understand in order to inform and regulate the deployment of deep-fakes in commercial products or clinical protocols. A recently emerging methodology for doing so is that of experimental ethics, in which moral judgements about various situational vignettes are collected from relatively large samples of online participants. In recent years, this methodology has been applied to quantify societal attitudes towards new technologies such as autonomous vehicles [16] or brain stimulation [26], potential public policies such as legalizing payments to kidney donors [27], but also downright futuristic scenarios such as mind upload [28], sex robots [29] or cognitive enhancement with brain implants [30] (figure 1d). The experimental ethics approach allows comparing different situation variants that may make or break dilemmas (e.g. whether imagining oneself as the conductor of an autonomous car changes one's attitude to how to reacts to accidents-[16]) and whether these effects are modulated by individual differences (e.g. whether a person's familiarity with science-fiction themes modulate their attitude towards robots- [29]).

Here, we employed the methodology of experimental ethics to gauge societal attitudes towards emotional voice transformation technology. We asked $N=303$ online participants to read 24 short text vignettes describing potential applications of vocal deep-fakes, and rate how morally acceptable they thought each scenario is. Participants were presented a cover story describing an imaginary hardware 


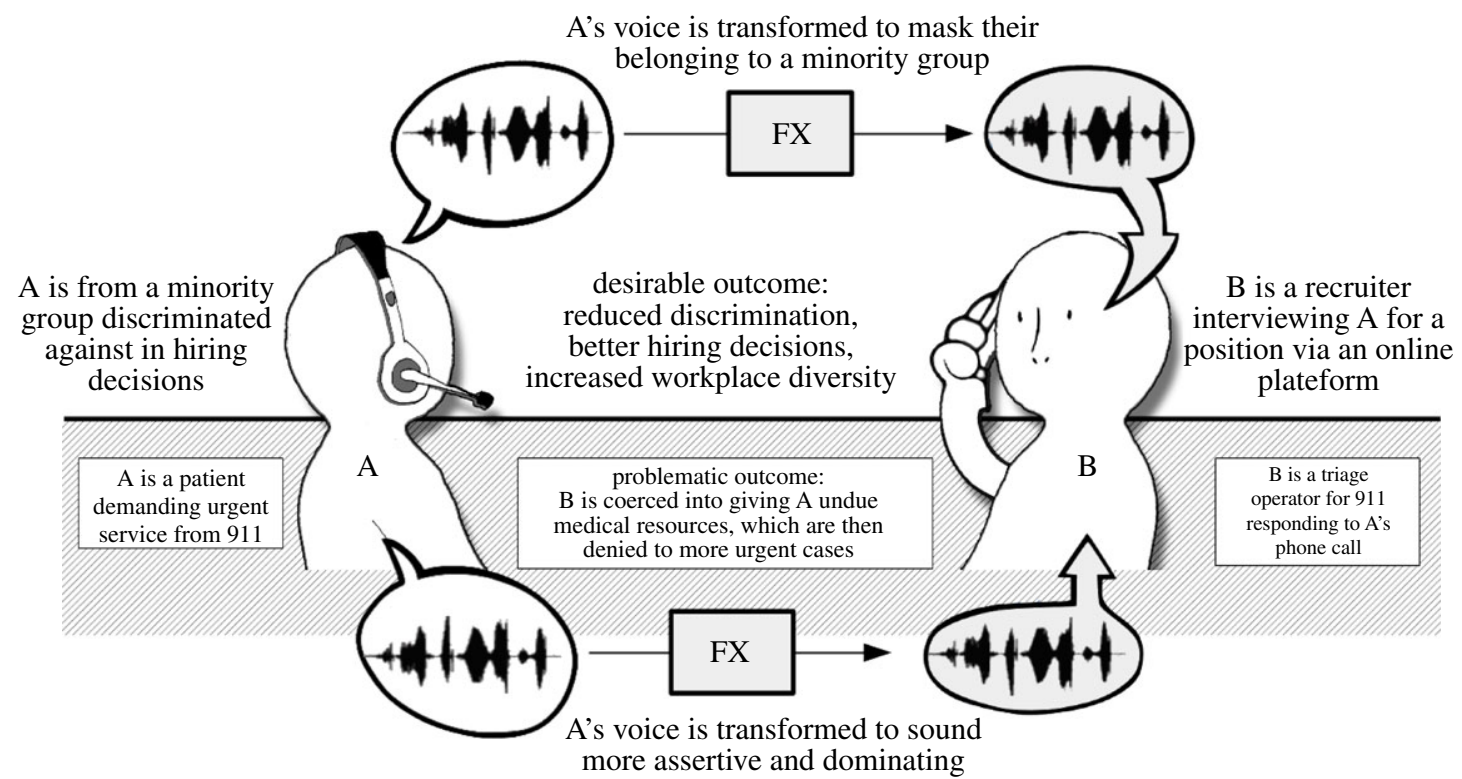

Figure 2. Very similar uses of voice transformation technology can lead to both desirable or problematic situations. Top: a voice transformation is used to mask the sex, accent or ethnicity of a user to eliminate discrimination in online hiring services. Situation inspired by genuine practice by the interviewing.io company [21]. Bottom: a voice transformation is used to increase the perceived dominance of a patient calling emergency medical services, who consequently gets undue medical resources from triage operators at the expense of other more urgent cases. Situation inspired by the authors' experimental work [20].

device (MyVoicePlus) able to transform the emotional quality of a voice in real-time, which was said to be currently considered by a startup company for commercial deployment in various situations. The vignettes describing potential applications of the device varied among four factors:

(i) whether the user of the device was the participant or an unknown other

(ii) whether the transformations were used therapeutically, or to enhance user capacities

(iii) whether the transformations operated on positive (enhancing smiling) or negative emotional expressions (reducing anxiety, reducing anger)

(iv) and whether the transformation affected how the user's voice is heard by others (i.e. the user's production), how the user hears other persons' voices (i.e. the user's perception), or whether it is used in a situation where the user hears their own manipulated voice (i.e. feedback).

For each vignette, participants first rated the acceptability of the situation, and were then presented with two potential dilemmas involving lying about the true purpose of the transformation in order to improve its effectiveness. Finally, for all of these judgements, we examined associations with individual differences in participants' attitudes towards morality (Moral Foundations Questionnaire MFQ [31], measuring factors of harm-care, fairness-cheating, loyalty-betrayal, authority-subversion and purity-degradation) and toward technology and science fiction (Science Fiction Hobbyism Scale SFH; [28]), two factors found relevant in previous research about the moral reception of new technologies [26,28,29,32] (See Methods for details of the procedure).

Although our study is exploratory and we did not preregister any formal hypotheses, a number of loose predictions can be made from the literature about how our variables of interest impact participants' moral judgements. First, similar experiments with emerging technologies such as autonomous vehicles [16] or brain stimulation [26] have documented situations of social dilemma, in which participants accept things for themselves (i.e. a car that favours its driver, rather than pedestrians) that they would otherwise reject for others. Second, across diverse forms of enhancement (e.g. memory, general intelligence, mood, etc.), participants are widely reported to be more comfortable with technologies that enhance capacities towards the norm (i.e. that are used therapeutically) than above the norm $[30,33]$. Finally, to the best of our knowledge, there is no straightforward equivalent in the literature of whether e.g. manipulating positive or negative emotions, or manipulating a user's perception or production, has any impact on participant's judgement of acceptability. Whether participants feel more comfortable with e.g. smiling or anxiety filters, and filters that affect their produced voice or their perception of how others sound, is an open non-trivial question [34], which our study wishes to address.

\section{Results}

\section{(a) Acceptability of overtly using the technology}

We first evaluated how morally acceptable our participants $(N=303)$ thought the use of a voice transformation device, when the true purpose of the technology was overtly known to all involved parties.

\section{(i) Voice transformations are in general well accepted in the population}

Across situations, the moral acceptability of overt vocal transformation was strongly significantly higher than neutral ( $M=6.49>5$; one-sample $t$-test against mid-point, averaging all acceptance scores across vignettes: $t(302)=146, p<0.001)$.

Because of heteroscedasticity (Breush-Pagan: $F(6,296)=$ $3.23, p=0.004)$, we tested the effect of individual characteristics on this judgement with multiple iterated re-weighted least squares (IRLS) regression (Huber weights, HC3 
(a)

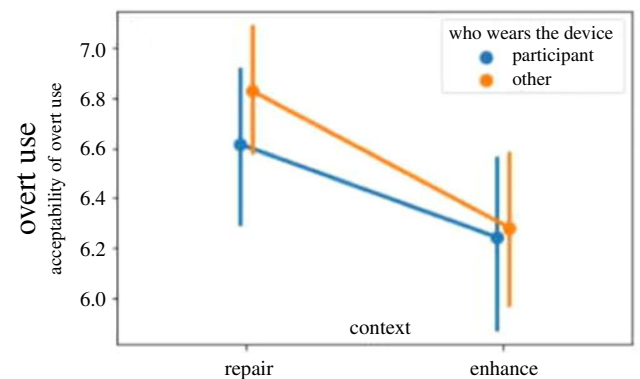

(d)

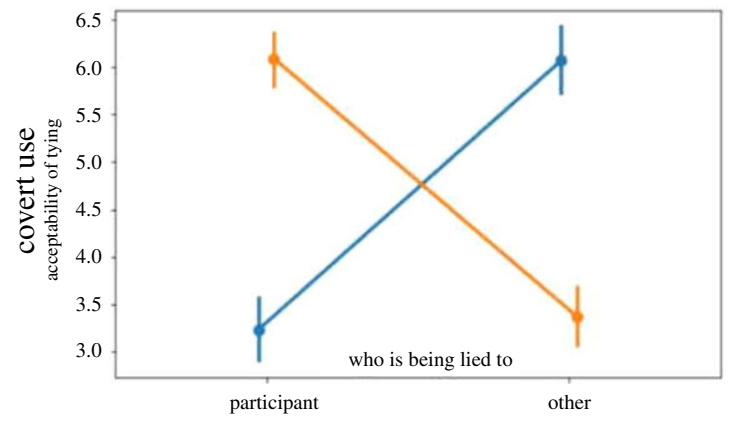

(b)

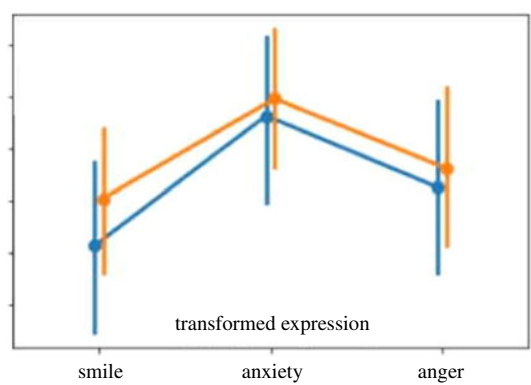

(e)

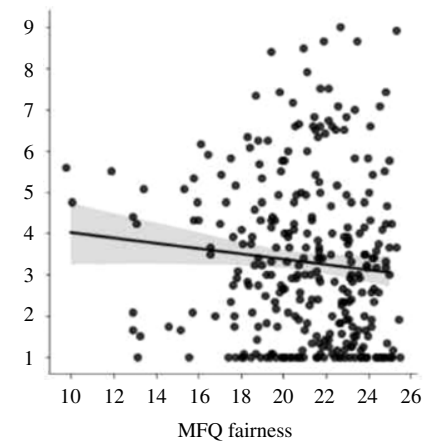

(c)

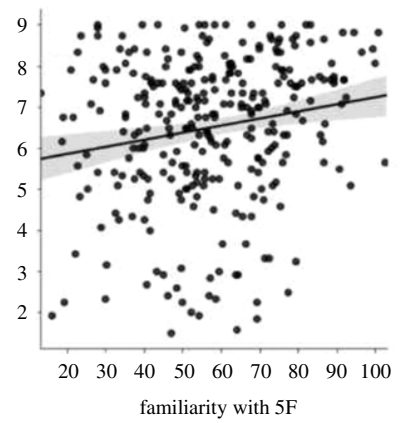

(f)

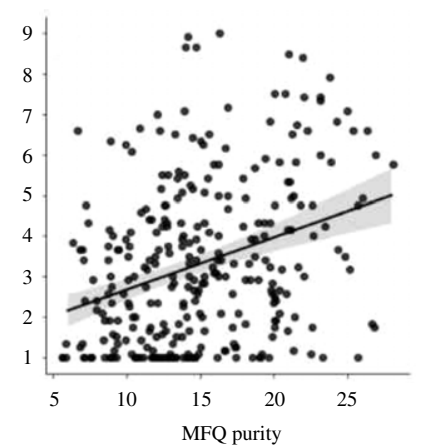

Figure 3. Moral judgements of overt and covert use of voice transformations. Top: Overt use. (a) The moral acceptability of overt vocal transformation was higher than the neutral midpoint, and therapeutic transformations even more so than transformations used to enhance user capacities. (b) Situations in which transformations aimed at weakening the two negative emotions of anxiety or anger were better accepted than situations in which transformations aimed to enhance smiling. (c) Across situations, acceptability was positively associated with the participants' familiarity with science-fiction. Bottom: Covert use involving lying about the true purpose of the transformation in order to improve its effectiveness. (d) Participants considered it morally acceptable that the user of the transformation hides its true purpose to others but hiding the transformation to the person using the device was totally unacceptable. (e-d) The acceptability of lying to the person using the device was negatively associated with the participants' concern with fairness, and positively with purity. $(a, b, d)$ Across conditions, there was no effect of whether the user of the device was the participant or an unknown other. Error bars: $95 \%$ confidence intervals. (Online version in colour.)

correction). Acceptability was significantly associated with positively associated with the participants' familiarity with science fiction $(\beta=0.014, z=2.75, p=0.006$; figure $3 c)$ and marginally positively associated to participant's reliance on MFQ purity $(\beta=0.04, z=1.85, p=0.064)$. No other MFQ factors regressed significantly (all $p \mathrm{~s}>0.1$ ). The marginal positive association with MFQ PU differed from others studies of similar technologies where purity was found negatively correlated with acceptability (e.g. mind upload [28]; sex robots [30]).

\section{(ii) A therapeutic context makes them even more acceptable}

We tested the effect of the goal to repair or enhance on situation acceptability by averaging within-participant scores for overt acceptability over therapeutic ( $n=6$ vignettes) and enhancing situations ( $n=6$ vignettes), and testing for population differences with a one-way repeated-measure ANOVA. Repair-enhance had a significant main effect on situation acceptability $(F(1,302)=47, p<0.001)$, with therapeutic situations $(M=6.7)$ being (even) more acceptable than enhancing situations $(M=6.2$; figure $3 a)$.

To test whether the effect of repair or enhance was associated with individual characteristics, we computed the within-participant difference between acceptability scores averaged over both types of vignettes, and computed multiple ordinary least-square (OLS) regression (Breusch-Pagan heteroscedasticity test: $F(6,296)=0.39, p=0.88)$. The better acceptability of repair situations was not significantly associated with individual differences in MFQ or Science fiction familiarity $\left(R^{2}=0.008, F(6,296)=0.38, p=0.89\right)$.

\section{(iii) Manipulating perception is less acceptable than manipulating production}

Similarly, we tested the effect of whether situations described voice transformation as affecting how the user's voice is heard by others (condition production: $n=4$ vignettes), how the user hears other persons' voices (condition perception: $n=4$ vignettes), or whether the user hears their own manipulated voice (condition feedback: $n=4$ vignettes) by averaging acceptability scores within-participant over the three types of vignettes and testing for population differences with a one-way repeated-measure ANOVA. There was a significant effect of the production-perception-feedback variable $(F(2$, $604)=7.5, \quad p=0.001$ ), with transformations affecting the user's production being more acceptable than perception and feedback. Both latter conditions share the fact that the device manipulates what the participant hears, regardless of whether it is the participant's own voice or that of another person.

We tested for associations with individual characteristics by computing the within-participant pairwise differences between acceptability scores averaged over all three types of vignettes, and computing multiple OLS regression (Breusch-Pagan heteroscedasticity test: perceptionproduction $F(6,296)=0.27, p=0.96$; feedback-production $F(6,296)=0.66, p=0.6815)$. The difference of acceptability between these situations was not associated with participant MFQ or SFH (perception-production: $R^{2}=0.006, F(6,296)=$ 0.31, $p=0.93$; feedback-production: $R^{2}=0.011, F(6,296)=$ $0.571, p=0.75)$. 


\section{(b) Acceptability of covert uses}

For each situation, we then tested the acceptability of lying about the true purpose of the device, in order to increase the transformation's effectiveness, in two situations which either involved the user's lying to their interlocutors, or the device's prescriber's lying to the user themselves. Because using the transformation overtly was generally well accepted (see above), and because we presented situations in a context where lying about the transformations would also improve their effectiveness (see Methods), these situations can be regarded as genuine moral dilemmas in which the deontologically blamable act of lying is balanced by the utilitarian value of the resulting improvement of performance.

\section{(i) Using the transformation covertly is not a problem..}

Although more acceptable situations were more acceptable to lie about (OLS regression over vignettes averaged between-participants: $R^{2}=0.61, F(1,22)=34.61, p<0.001$; Breusch-Pagan heteroscedasticity test: $F(1,22)=0.13, p=$ $0.72)$, lying was generally regarded as non acceptable by our participants $(M=4.69<5, t(302)=3.19, p=0.001)$.

However, there was a very large interaction with which person is being lied to (one-way rm-ANOVA: $F(1,302)=$ $631, p<0.001$; figure $3 d$ ): somewhat surprisingly, participants considered it morally acceptable that the user of this device hides its true purpose to others $(M=6.08$ [5.87, 6.3]; one-sample $t$-test against mid-point: $t(302)=9.99, p<0.001$ )

Because of marginal heteroscedasticity (Breusch-Pagan: $F(6,296)=1.72, p=0.11)$, we tested the association of the acceptability of users' lying to others with individual characteristics with multiple IRLS regression. The acceptability of lying to others was not found associated with any of the MFQ subscales (best, PU: $\beta=0.033, z=1.33, p=0.18$ ), but was positively influenced by science fiction familiarity $(\beta=0.01, z=1.95, p=0.05)$.

\section{(ii) ... unless it is hidden from the user of the device}

However, hiding the transformation to the person using the device appeared totally unacceptable $(M=3.3<<5$, onesample $t$-test against mid-point: $t(302)=-14.9, p<0.001$ ), even though the transformation was presented as more effective for the user when doing so (figure $3 d$ ).

As above, we tested the association of the acceptability of lying to the device's user with individual characteristics, using with multiple IRLS regression (Breusch-Pagan heteroscedasticity test: $F(6,296)=1.28, p=0.26)$. The low acceptability of lying to the user was driven (i.e. negatively associated) by participants high on the MFQ subscale of fairness ( $\beta=-0.1395 ; z=-3.461, p=0.001$; figure $3 e$ ) but attenuated (i.e. positively associated) for participants high on MFQ purity $(\beta=0.0930, z=3.65, p<0.001$; figure $3 f)$ and loyalty $(\beta=0.09, z=2.71, p=0.007)$. The acceptability of lying to the user was also associated with science fiction familiarity $(\beta=0.014, z=2.38, p=0.017)$, with greater familiarity making lying to the user more acceptable.

\section{(c) Acceptability of voice transformations is not influenced by seeking self profits}

To test for the effect of either depicting situations where the user was the participant or an unknown person, we conducted a mixed ANOVA with self-other as a between-participant factor, and vignette conditions (repair-enhance, positivenegative transformation, production-perception-feedback) as within-participant factors. There was no statistical difference of acceptability between overt situations which depicted the participant as the user benefiting of the device $(M=6.43)$, and situations where the user was an unknown person $(M=$ 6.55; no main effect, $F(1,301)=0.37, p=0.54$ ). Neither did the effect of self-other interact with any of the other variables: regardless of whether the user was themselves or others, participants thought similarly of differences between situations meant to repair and enhance (no interaction self - other $x$ repair - enhance: $F(1,301)=1.68, p=0.20$; figure $3 a$ ), of differences between situations involving smiling, anger or anxiety (no interaction self - other $\times$ transformation: $F(1,301)=1.43$, $p=0.23$; figure $3 b$ ), and of differences between devices affecting the user's production, perception or feedback (no interaction self-other $\times$ production-perception $-\mathrm{fb}: F(2$, 602) $=0.047, p=0.95$ )

Similarly, participants did not judge less acceptable the covert situations where they were hidden the true purpose of the device (regardless of whether they were its user, or not), compared to situations where it was hidden to unknown others (rm-ANOVA, with concealed participant-other as within-participant factor, $F(1,302)=0.0026$, $p=0.87$; figure $3 d$ ). In other words, the relatively high acceptability of users' lying to others did not depend on whether the participant was the user of the device or the person to whom the transformation is hidden from; and the low acceptability of lying to the device's users did not depend either on whether the user was the participant themselves or an unknown other.

In sum, contrary to situations like e.g. pedestrian dilemmas in autonomous vehicles [16], there was radically no evidence of social dilemma regarding the use of voice transformations, in which one would e.g. accept for themselves what they would blame for others, even in situations involving the blamable act of lying.

\section{(d) The nature of the emotion impacts the moral acceptability of the transformation}

Finally, we tested the impact of what emotion is transformed on the acceptability of the situation, as well as the interaction with repair-enhance factor. We averaged within-participant scores of overt acceptability over repair - enhance situations concerning anxiety ( $n=4$ vignettes; repair: 2$)$, anger $(n=2$ vignettes; repair: 1$)$ and smile vignettes ( $n=6$; repair: 3$)$, and tested for population differences with a two-way rm-ANOVA.

There was a main effect of emotion: situations in which transformations aimed at weakening the two negative emotions of anxiety $(M=6.8)$ or anger $(M=6.5)$ were better accepted than situations involving transformations enhancing smile $(F(2,604)=24.47, p<0.001)$, although the latter remained well accepted at $M=6.3$ (figure $3 b$ ).

The effect of emotion also interacted significantly with the repair-enhance factor $(F(2,604)=21.3, p<0.001)$, with transformations aiming to weaken negative emotions benefiting more of the therapeutic condition $(\Delta=+0.56)$ than the transformation targeting positive emotions $(\Delta=+0.35)$. The effect was maximal for the repairment of anxiety (Repair: $M=7.17$; Enhance: $M=6.34$ ).

Similarly, in covert situations, it was more more acceptable to hide the purpose of a transformation aiming to 
weaken negative emotions than a transformation aiming to enhance smile (one-way rm-ANOVA; main effect of transformation: $F(2,604)=8.3, p<0.001)$.

Finally, we tested whether these differences between positive and negative transformations were associated with individual differences, by computing the within-participant pairwise differences between acceptability scores averaged over all three types of transformations, and computing multiple OLS regression (Breusch-Pagan heteroskedasticity test: anxiety-smile $F(6,296)=0.59, p=0.74 ;$ anger-smile $F(6$, $296)=0.73, p=0.62)$. The difference of acceptability between these situations was not associated with participant MFQ or SFH (anxiety-smile: $R^{2}=0.031, F(6,296)=1.58, p=0.15$; anger-smile: $\left.R^{2}=0.023, F(6,296)=1.137, p=0.34\right)$.

\section{Discussion}

We reported here on an experimental ethics study in which $N=303$ online participants evaluated the acceptability of vignettes describing potential applications of expressive voice transformation technology. We found that vocal deep-fakes were generally well accepted, notably in a therapeutic (versus enhancement) context; when they corrected negative emotions rather than enhanced positive emotions; and when they manipulated a speaker's production rather than perception. Surprisingly, transformations remained well-accepted even when the user lied to their interlocutors about using them and, unlike other emerging technologies like autonomous vehicles, there was no evidence of social dilemma in which one would e.g. accept for others what they resent for themselves. The only real moral objection to vocal transformations appeared related to situations in which they were applied to a speaker without their knowing, with the acceptability of such situations being modulated by individual differences in moral values and attitude towards science-fiction.

The fact that voice transformations are generally wellaccepted, with average scores across situations well above the scale mid-point, first and foremost shows that the western, young, educated population studied here is sympathetic to the idea of customizing one's own emotional expression with technology, when these technologies become available. This attitude, at least for the range of scenarios tested here, seems consistent with transhumanistic views for which technology should be used to enhance human capacities and improve happiness [35] as well as control for emotional or neurological limitations (e.g. taking anti-love drugs to curb affect in divorce situations [36]).

Contrary to other moral psychology studies where individual attitudes to MFQ Purity negatively correlated with e.g. acceptability of cognitive enhancement or mind upload [28], acceptability here was facilitated by the participants' reliance on the purity dimension. This may suggest that voice transformations are not seen as a breech of human integrity, but rather as a way to improve control and self-determinacy (i.e. an anthropotechnical tool for self-customization [37]). In a contemporary society promoting continuous self improvement, the good reception of this kind of technology is thus perhaps not surprising [38]. However, it should be noted that the MFQ purity construct has come under recent debate (e.g. it may be interpreted differently by religious and non-religious individuals [39]), and further research is needed to ascertain what this construct measures in our specific sample of participants.
The good general acceptance of voice transformations was further improved in therapeutic situations, which were judged more acceptable that situations merely aiming to enhance user capacities [40]. This attitude is consistent with what is reported in other empirical studies of cognitive enhancement [26,30,33], and with imperatives put forward by the bioethics literature [41,42]. It confirms that the therapy-enhancement distinction is morally salient to the public concerning potential display of expressive voice transformation technology.

Acceptance was also higher for situations which manipulated the production of an expression than situations which manipulating its perception. That participants should be biased against the latter somehow contradicts the expectation that covert changes that are internal to the individual would have less broad impact on others than changes affecting their outward expression [43]. This preference may reflect a worry about having one's real experience distorted, as one could worry e.g. about mood-enhancers drugs such as SSRIs altering one's sense of living truly (is it me or the Prozac enjoying this? $[40,44])$, even though in the case of Prozac these bioethical concerns do not seem shared by the general population [45]. Since the production and perception situations could be compared respectively with the use of Instagram filters (which are now common; figure 1c) over augmented-reality (AR) glasses (which aren't yet), it would be interesting to follow up on these results in the next few months, as several announced AR devices such as Apple Glasses may gain popularity and modify these attitudes ([46]; see also below about science-fiction familiarity).

In a second set of questions, we collected judgements about concealed-use situations, and presented them in a context where lying about the transformations would also improve their effectiveness (see Methods Judge how acceptable it is to lie to your entourage [.. $]$, knowing that this would improve the effectiveness of the device). The fact that voice transformations are generally thought desirable in 'overt' situations makes these 'covert' situations appear as genuine moral dilemmas, in which the deontological imperative against lying is balanced against the utilitarian benefits of selfimprovement. For these situations, both sides of the debate were clearly reflected in participant judgements: one the one hand, acceptance of lying was negatively associated with MFQ fairness; on the other hand, as was the case of overt situations, acceptance scores for these situations were also positively associated with MFQ purity, which attenuated the generally low acceptability of covert use.

Strikingly though, in all of these dilemma as well as in the less problematic 'overt' situations, we found radically no evidence of a social dilemma where one would e.g. refuse for oneself what they think acceptable for others. This held whether participants envisioned to modify their own voice, or that of others; and whether participants were being lied to regarding their perception, or whether they lied to others. This absence of effect of who benefits from the device when judging its acceptability is in stark contrast with typical sacrificial scenarios (like the trolley problem or, more recently, pedestrian versus driver dilemma in autonomous vehicles), in which participants tend to value selfpreservation [16,47]. This suggests that participants judge voice-transformation technology primarily with a utilitarian perspective, treating the welfare of everyone as of equal importance, 'from the point of view of the universe' [48] 
regardless of whether they are near or far, our children and friends or absolute strangers, human or animal [43]. While this doesn't mean that self-preservation biases could not be created, for instance for situations involving finite supply [26] or larger individual cost [16], the fact that voice transformation should be judged so impartially suggests that there currently is no social obstacle to the massive deployment of such technologies in (here, western) societies.

Even though there was no effect of self-other, covert dilemma were very strongly biased against lying to the person wearing the prosthesis (i.e. regardless of who that person was: self or other). This attitude may be an effect of describing the device in our cover story as a physical prosthesis, for which 'installing' it covertly would be seen as an unacceptable breach of consent-autonomy [49]. To control for physicality, future work could e.g. extend this study to assess the acceptability of software effects (filters) deployed in virtual meeting software.

Unexpectedly, transformations aiming to enhance positive expressions (smiles) were judged less acceptable than those aiming to reduce negative expressions (anxiety, anger). This asymmetric pattern of result contrasts with a purely hedonic view, in which making people 'feel as good as possible, and feel least bad' [50] would be equally valued. Rather, it may indicate that curbing negative expressions is valued less for the gain of valence than for an Aristotelician inclination for control over oneself, because negative emotions such as portrayed here (stress, anxiety, fear) are viewed as less deliberate and more automatic than smiling [51]. This view is also consistent with our interpretation of MFQ purity as valuing selfdeterminacy. If true, this may prefigure a situation where, when broadly adopted, expressive technology would shift the moral responsibility associated to certain emotions or behaviours: expressions which were once normal to not control (e.g. one cannot be blamed for stress [51]) may become controllable, and thus blamable and subjected to social demand (e.g. 'why didn't you put stress-control on?', [52]). To further test this idea, it would be interesting to examine scenarios involving non-deliberate positive expressions (eg. using a transformation to avoid giggling uncontrollably at a funeral) or to examine how the present results are modulated by cultural differences in emotional display norms [53].

Finally, across-the-board positive associations with the participants' familiarity with science-fiction indicate a robust effect of cultural conditioning on the acceptance of voice transformation technology. As already remarked for brain implants [28] or cognitive enhancement [30], exposure to futuristic themes and ideas appears associated with less resistance to technologies which challenge our conception of human nature. The influence of science-fiction themes is already well studied as a source of inspiration for real-world technological innovation, e.g. in space [54] or nanotechnologies [55], but it appears that it also plays a role in the reception of new technology by the general public [56]. One consequence is that the attitude towards voice transformations may co-vary with cultural differences in attitudes towards new technology (e.g. robots in Japan [57]).

One obvious limitation of this work is our focus on a sample of predominantly young and educated western participants (i.e. college students), which is representative neither of the generation population in western countries (as would e.g. survey pools constructed to match the composition of a given adult population by gender, age, education and ethnicity - [27]), nor of the more global non-WEIRD population [58]. Although research suggests that instruments such as the MFQ are relatively stable across cultures [59], there is an emerging corpus of work attempting to diversify in moral psychology research samples [60,61], and to conduct cross-cultural comparisons with massive online methodologies [62]. Such initiatives will be particularly needed when evaluating the acceptability of information technologies such as deep-fakes, which are spreading equally fast in western and non-western countries [63].

The use of vignettes in experimental ethics approaches also comes with several limitations. First, the intensity of reactions elicited by the stories may be limited by the immersion of the participant, or the vividness of their imagination [30], and reading a vignette, especially one describing an intense emotional situation, may not elicit reactions as strong as in the corresponding real-life situations [64]. Here, we moderate these limitations by including an elaborate cover story presenting the device as being considered for commercialization by an actual voice technology company, and stating that participant responses will weight in future commercial decisions. Second, all of these scenarios consider idealized transformations which are assumed to be non-identifiable as fake, and properly recognized as their intended emotion. As these technologies soon become available, future work could consider measuring reactions to more tangible situations (e.g. upon hearing one's own voice modified by the device), studying situations in which voice transformations are not recognized as genuine behaviour (e.g. how comfortable am I to use a filter than may sound robotic at times?), or combining the approach with qualitative ethnographic methods documenting the appropriation of the device by potential users (e.g. how real callcentre operators end up using a smile transformation) [65]. Finally, it should also be noted that, even though we designed the present 12 vignettes to span a wide range of situations, it remains an open question whether our conclusions generalize to other types of vocal deep-fakes, and/or other types of situations than those tested here.

Feelings and emotions are at the forefront of the political behaviour of citizens and policy makers [66]. It will be essential for our societal future to clarify the determinants of moral judgements about technologies able to customize and control these behaviours, in order to guide norm-setting regarding their applications.

\section{Material and methods}

\section{(a) Participants}

$N=303$ participants $(M=25.7$; female: 156$)$ took part in an online study, administered via a Qualtrics questionnaire (Qualtrics International Inc., Seattle, WA). All were French residents, recruited by the INSEAD-Sorbonne Université Behavioural Laboratory among a population consisting mainly of university students. 213 participants $(70.3 \%)$ had completed at least a Bachelor's degree, and 116 $(38 \%)$ had at least a Master's degree. Participants were randomised into one of two self-other conditions. For each condition, participants were presented 12 vignettes of scenarios assessing three within-factors factors tested for their possible impact on moral acceptability (see details of vignettes below). For each vignette, participants answered three questions about their perceived moral acceptability of the situation (see Measures below), which creates a total of 36 answers for each participant. 


\section{(b) Procedure}

Participants were initially presented a cover story describing an imaginary hardware device able to transform the emotional quality of a voice in real-time, both in the user's voice (for others to hear) and in the user's ear (i.e. transforming the emotions of others' voices). The device, named 'MyVoicePlus', was presented as being considered for possible commercial and/or clinical deployment by a French startup company. The cover story included mock photographs of the device (consisting of both an in-ear prosthesis and a larynx piece, disguised as jewelry), as well as references to technical voice-transformation literature (e.g. [67]) allegedly describing the algorithms implemented in the device (see electronic supplementary material). Participants were told that the startup was commissioning the study to evaluate the societal acceptability of their technology in various usage scenarios, and that their collective judgements would condition the deployment of the technology.

After reading the cover story, participants were presented a series of $n=12$ short situational vignettes, each describing a potential application of the voice-transformation device (see Vignettes, below). There were two between-participant conditions, in which participants either read vignettes that described the participant as the user of the device (condition self; $N=150$ ), or vignettes describing otherwise-identical situations in which the device was applied to others and in which participants were in the position of the user's conversation partners (condition other; $N=153$ ). In each self-other condition, vignettes included a number of within-participant conditions, which we describe below. For each vignette, participants were asked to answer three questions about how morally acceptable they think the situation was (see Measures, below).

Finally, after completing the questions for all vignettes, participants were asked to complete two standard questionnaires measuring attitudes towards morality (Moral Foundations Questionnaire MFQ; [31]) and toward technology and science fiction (Science Fiction Hobbyism Scale; [28]). The study lasted on average $30 \mathrm{~min}$.

\section{(c) Vignettes}

We created $n=12$ short text vignettes describing potential applications of the voice-transformation device in concrete daily life situations. Vignettes varied among three situational factors, which were encoded as within-participant variables to test for their impact on the acceptability of the device:

(i) whether voice transformations are used to repair (e.g. therapeutically) or enhance user capacities (condition repair: $n=6$; enhance: $n=6$ ). Examples of repair vignettes included e.g. using the device to help a depressive patient communicate with their close ones with a more enthusiastic tone of voice; examples of enhance situations included e.g. using the same transformation to help a politician gather more following. In repair vignettes, the device was described as being prescribed to the user by a doctor; in enhance vignettes, the device was recommended by a life coach.

(ii) the kind of voice transformation operated by the device, either reducing anger ( $n=2$; e.g. making angry customers' voice less taxing to attend to, for call-centre operators), reducing anxiety ( $n=4$; e.g. helping a budding actor overcome stage-fright) or enhancing smile $(n=6$; e.g. helping a waiter gather more tips from customers).

(iii) whether the voice transformation affects how the user's voice is heard by others (condition production: $n=4$ ), how the user hears other persons' voices (condition perception: $n=4)$, or whether it is used in a situation where the user hears their own manipulated voice (condition feedback: $n=4)$. Examples of the feedback condition include e.g. having a post-traumatic stress disorder (PTSD) patient listen to their own voice made less anxious as they retell their traumatic event [68].

All 12 vignettes were written in two matched versions, in which the user of the device was either the participant (e.g. imagine you are a depressive patient, and your doctor is advising you to use a voice-transformation device.. ; condition self : $n=12$ ) or an unknown other (e.g. A depressive patient . . ; condition other: $n=12$. Condition self-other was randomly assigned between-participant; all other conditions were varied within-participant, in random order. All vignettes are available with English translation in electronic supplemental material.

\section{(d) Measures:}

After reading each vignette, participants answered three questions about:

(i) how morally acceptable they think the situation is (Judge how morally acceptable it is to use the MyVoicePlus device in such a situation'; FR: A quel point jugez-vous cette utilisation du produit MyVoicePlus ${ }^{\mathrm{TM}}$ moralement acceptable?)

(ii) how morally acceptable they think it would be for the user to use the device covertly, i.e. to lie to their conversation partners that they are either talking to them, or hearing them, with a modified voice, knowing that this may improve the effectiveness of the device by up to 70\%. (Judge how acceptable it is to lie to your entourage about using the voice transformation, knowing that this would improve the effectiveness of the device'; FR: 'A quel point jugez-vous acceptable le fait de cacher-votre entourage l'existence de la transformation de voix, en sachant que cela augmente considérablement l'efficacité du dispositif?)

(iii) how morally acceptable they think it would be to hide the true purpose of the device from its own user, i.e. that the users themselves do not know that they either talking, or hearing others, with a modified voice. (Judge how acceptable it is that the [doctor/coach] should lie to the user about the voice transformation, knowing that this would improve the effectiveness of the device'; FR: A quel point jugez-vous acceptable le fait que le médecin vous cache l'existence de la transformation de voix, en sachant que cela augmente considérablement son efficacité?)

Answers to all three questions were rated using a 9-point Likert scale, anchored by 1 totally unacceptable and 9 totally acceptable.

\section{(e) Attitude questionnaires}

In addition to providing moral judgements about the vignettes, participants completed two questionnaires measuring their attitudes toward morality (Moral Foundations Questionnaire MFQ; [31]) and toward technology and science fiction (Science Fiction Hobbyism Scale SFH; [28]).

The MFQ consists in 32 short questions (30 items +2 foil items) about how relevant various considerations (e.g. Whether or not someone suffered emotionally) are when deciding whether something is right or wrong, rated from 1 (not at all relevant) to 7 (extremely relevant), and how much the participant agrees with various moral positions (e.g. Compassion for those who are suffering is the most crucial virtue; rated from 1 (strongly disagree) to 7 (strongly agree). In accordance with typical MFQ analysis [31], we grouped and averaged each participant responses along the five subscales of care-harm (6 items; e.g. whether or not someone suffered emotionally), fairness-cheating (5 items; e.g. whether or not some people were treated differently from others), loyalty-betrayal 
(6 items; e.g.whether or not someone did something to betray their group), authority-subversion (5 items; e.g. whether or not an action caused chaos or disorder), and purity-degradation (6 items; e.g. whether or not someone violated standards of purity and decency). None of the items were reverse-coded. In this work, we used the back-translated French-language version of the MFQ designed by [69]. A previous study [69] validated MFQ-French on a sample of similar demographics as the present study and found it had acceptable internal validity $(N=538$ participants; care: Cronbach $\alpha=0.64$; fairness: $\alpha=0.67$; loyalty: $\alpha=0.65$; authority: $\alpha=0.73$; purity: $\alpha=0.79$ ) and one-month test-retest validity $(N=40 ; \quad$ care: $r=0.53, \quad 95 \% \quad$ CI $[0.26,0.72]$; fairness: $r=0.66,[0.43,0.80] ;$ loyalty: $\quad r=0.66,[0.44,0.81]$; authority: $r=0.75$, [0.57, 0.86], purity: $r=0.88,[0.78,0.94]$; all $p s<0.01$ ). The fit to a 5 -factor structure, while significantly better than an alternative 3-factor model, was comparably poorer $(N=538$; Comparative Fit Index CFI: 0.82; Root mean squared error of approximation RMSEA: 0.065), a known issue common to the American version and discussed elsewhere [70,71].

In accordance with recommendations of [69] and compared to the American version, two MFQ items (fairness: I think it's morally wrong that rich children inherit a lot of money while poor children inherit nothing'; authority: 'Men and women each have different roles to play in society) were removed from the French translation to improve internal consistency. In our data $(N=303)$, the internal validity of the $5 \mathrm{MFQ}$ constructs was comparable to the sample of [69] for purity-degradation $(\alpha=0.74,[0.70,0.78])$, fairness-cheating $(\alpha=0.65,[0.58,0.70])$, loyalty-betrayal $(\alpha=$ $0.63,[0.56,0.69])$ and authority-subversion $(\alpha=0.68,[0.62$, $0.73]$ ), but was poor for the care-harm construct $(\alpha=0.55,95 \%$ CI $[0.45,0.61])$. Confirmatory factor analysis for the 5-factor model was significant (GLS fit, $\chi^{2}(340)=575, p<0.001$ ), fitting data adequately on some measures (RMSEA $=0.048$ ) but relatively poorly on others $(\mathrm{CFI}=0.48)$. We opt to conform to the recommendations of a more extensive validation (with a sample size nearly twice as big as our current sample [69]) and use the 5-factor model for our current analysis. However, the present data adds evidence to the fact that, as already discussed elsewhere [71], significant elements of the MFQ covariance structure are not captured by this model.

The SFH scale [28] consists of 12 items and measures individuals' cultural exposure to futuristic technology and science fiction themes (examples of items: I often think about what machines are like in the future, I often spot science or technology related errors in science fiction films, TV series, or books'). All items are rated from 1 (strongly disagree) to 7 (strongly agree), with higher scores indicating higher science fiction familiarity. None of the items were reverse-coded. A previous study [29] validated the scale on $N=172$ participants and found it had good psychometric properties (all factor loadings $>0.57$; Cronbach's $\alpha=0.92$ ). In this work, we used our own, non-validated French-language translation of the SFH. In our data $(N=303)$, the internal validity of the SF construct was also good $(\alpha=0.89,[0.888,0.898])$. (f) Statistical analyses

There were two dependent variables (DVs) in the study, measuring the acceptability of overt (DV1) and covert (DV2) use of voice transformations. DV2 was constructed by recoding the two questions about concealed use (lying to the user, and lying to others) as a single DV measured in two conditions (who is being lied to).

The study's vignettes spanned a number of situation characteristics, each described as a combination of independent variables (IVs). There were one between-participant IV (self-other), three within-participant IVs for DV1 (repair-enhance, smile-anxietyanger, production-perception-feedback) and an additional two within-participant IVs for covert DV2 (lying to user-other, and lying to participant-other). We analysed the effect of IVs on both DVs using one-way, repeated-measures or mixed ANOVAs, by averaging acceptability scores within-participant over the vignettes corresponding to each condition tested.

In addition, there were six measures of individual characteristics (MFQ: 5 constructs; SFH: 1 construct). We tested the association of these individual characteristics with the study's DVs by computing within-participant averages of acceptability scores (one data point per participant) and multiple regression. We tested for residual-prediction heteroscedasticity with the Breusch-Pagan test. In case of homoscedasticity, we used multiple ordinary least square (OLS) regression; in case of heteroscedasticity, we used iterated re-weighted least-square (IRLS) regression with Huber weighting and HC3 correction. All analyses were conducted in Python (3.6.8), using the pingouin (0.3.12) and statsmodels (0.12.2) packages.

Ethics. All participants tested at the Sorbonne-INSEAD Center for Behavioral Science. The experiment was approved by the Institut Européen d'Administration des Affaires (INSEAD) IRB (Study 202058; 'Study of the moral attitudes and willingness towards the use of a voice transformation device'; decision of 18 June 2020). All participants gave their informed consent for the study, were debriefed after the study, and were compensated for their participation at a standard rate.

Data accessibility. Experimental data and analysis code (open-source, Python) made available as electronic supplementary material at https://github.com/creamlab/deep-ethics.

Authors' contributions. N.G. and J.J.A. designed the study and analysed data. N.G. and J.J.A. wrote the manuscript, with contributions from G.V.

Competing interests. J.J.A. is scientific advisor for voice transformation start-up Alta Voce SAS.

Funding. Study funded by European Research Council Starting Grant CREAM 335634, Proof of concept grant ACTIVATE (875212), Agence Nationale de la Recherche PRC grants REFLETS and SEPIA, and Fondation Pour l'Audition (FPA RD-2018-2).

Acknowledgements. The authors thank Gilles Degottex and Marco Liuni (Alta Voce SAS) for comments on the design of the study and Pablo Arias (Lund University/IRCAM) for help with data analysis.

\section{References}

1. Darwin C. 1872 The expression of the emotions in man and animals, 1998 edn. Oxford, UK: Oxford University Press.

2. Knapp ML, Hall JA, Horgan TG 2013 Nonverbal communication in human interaction. Cengage Learning.

3. Bachorowski J-A, Owren MJ. 1995 Vocal expression of emotion: acoustic properties of speech are associated with emotional intensity and context.
Psychol. Sci. 6, 219-224. (doi:10.1111/j.1467-9280. 1995.tb00596.x)

4. Jack RE, Sun W, Delis I, Garrod OGB, Schyns PG. 2016 Four not six: revealing culturally common facial expressions of emotion. J. Exp. Psychol.: General 145, 708. (doi:10.1037/xge0000162)

5. Oosterhof NN, Todorov A. 2008 The functional basis of face evaluation. Proc. Natl Acad. Sci. USA 105, 11 087-11 092. (doi:10.1073/pnas.0805664105) 
8. Goupil L, Ponsot E, Richardson D, Reyes $G$, Aucouturier J-J. 2021 Listeners' perceptions of the certainty and honesty of a speaker are associated with a common prosodic signature. Nat. Commun. 12, 1-17. (doi:10.1038/s41467-020-20649-4)

9. Jack RE, Garrod OGB, Yu H, Caldara R, Schyns PG. 2012 Facial expressions of emotion are not culturally universal. Proc. Natl Acad. Sci. USA 109, 7241-7244. (doi:10.1073/pnas.1200155109)

10. Safra L, Chevallier C, Grèzes J, Baumard N. 2020 Tracking historical changes in trustworthiness using machine learning analyses of facial cues in paintings. Nat. Commun. 11, 1-7. (doi:10.1038/ s41467-020-18566-7)

11. Arias P, Rachman L, Liuni M, Aucouturier J-J. 2020 Beyond correlation: acoustic transformation methods for the experimental study of emotional voice and speech. Emotion Rev. 13, 12-24. (doi:10.1177) 1754073920934544)

12. Rachman L et al. 2017 David: an open-source platform for real-time transformation of infrasegmental emotional cues in running speech. Behav. Res. Methods 1-21.

13. Westerlund M. 2019 The emergence of deepfake technology: a review. Technol. Innovation Manage. Rev. 9. (doi:10.22215/timreview/1282)

14. Pumarola A, Agudo A, Martinez AM, Sanfeliu A, Moreno-Noguer F. 2018 Ganimation: anatomicallyaware facial animation from a single image. In Proc. of the European Conf. on Computer Vision (ECCV), pp. 818-833.

15. Luo Z, Chen J, Takiguchi T, Ariki Y. 2017 Emotional voice conversion using neural networks with arbitrary scales fo based on wavelet transform. EURASIP J. Audio, Speech Music Process. 2017, 1-13. (doi:10.1186/s13636-016-0099-4)

16. Bonnefon J-F, Shariff A, Rahwan I. 2016 The social dilemma of autonomous vehicles. Science 352, 1573-1576. (doi:10.1126/science.aaf2654)

17. Porter S, Brinke LT. 2008 Reading between the lies: identifying concealed and falsified emotions in universal facial expressions. Psychol. Sci. 19, 508-514. (doi:10.1111/j.1467-9280.2008.02116.x)

18. Tang C, Seal CR, Naumann SE. 2013 Emotional labor strategies, customer cooperation and buying decisions. J. Manage. Market. Res. 13, 1.

19. Côté S, Hideg I, Van Kleef GA. 2013 The consequences of faking anger in negotiations. J. Exp. Soc. Psychol. 49, 453-463. (doi:10.1016/j. jesp.2012.12.015)

20. Boidron L, Boudenia K, Avena C, Boucheix J-M, Aucouturier J-J. 2016 Emergency medical triage decisions are swayed by computer-manipulated cues of physical dominance in caller's voice. Sci. Rep. 6, 1-7. (doi:10.1038/srep30219)

21. Lerner A. We built voice modulation to mask gender in technical interviews. here's what happened. Accessed from https://blog.interviewing. io/we-built-voice-modulation-to-mask-gender-intechnical-interviews-heres-what-happened on 2021-03-16.

22. Nijboer F, Morin F0, Carmien SP, Koene RA, Leon E, Hoffmann U. 2009 Affective brain-computer interfaces: psychophysiological markers of emotion in healthy persons and in persons with amyotrophic lateral sclerosis. In 2009 3rd Int. Conf. on Affective Computing and Intelligent Interaction and Workshops, pp. 1-11. IEEE

23. Bovens L. 2009 The ethics of nudge. In Preference change, pp. 207-219. New York, NY: Springer.

24. Rohrmann S, Bechtoldt MN, Hopp H, Hodapp V, Zapf D. 2011 Psychophysiological effects of emotional display rules and the moderating role of trait anger in a simulated call center. Anxiety, Stress \& Coping 24, 421-438. (doi:10.1080/10615806. 2010.530262)

25. Goupil L, Johansson P, Hall L, Aucouturier J-J. 2021 Vocal signals only impact speakers' own emotions when they are self-attributed. Conscious Cogn. 88 103072. (doi:10.1016/j.concog.2020.103072)

26. Medaglia JD, Yaden DB, Helion C, Haslam M. 2019 Moral attitudes and willingness to enhance and repair cognition with brain stimulation. Brain Stimulat. 12, 44-53. (doi:10.1016/j.brs.2018. 09.014)

27. Elias JJ, Lacetera N, Macis M. 2019 Paying for kidneys? A randomized survey and choice experiment. Am. Econ. Rev. 109, 2855-2888. (doi:10.1257/aer.20180568)

28. Laakasuo M, Drosinou M, Koverola M, Kunnari A, Halonen J, Lehtonen N, Palomäki J. 2018 What makes people approve or condemn mind upload technology? Untangling the effects of sexual disgust, purity and science fiction familiarity. Palgrave Commun. 4, 1-14. (doi:10.1057/s41599018-0124-6)

29. Koverola M, Drosinou M, Palomäki J, Halonen J, Kunnari A, Repo M, Lehtonen N, Laakasuo M. 2020 Moral psychology of sex robots: an experimental study- how pathogen disgust is associated with interhuman sex but not interandroid sex. Paladyn J. Behav. Rob. 11, 233-249. (doi:10.1515/pjbr2020-0012)

30. Koverola $M$, Kunnari $A$, Drosinou $M$, Palomäki J, Hannikainen IR, Sundvall J, Laakasuo M. 2020 Nonhuman superhumans-moral psychology of brain implants: exploring the role of situational factors, science fiction exposure, individual differences and perceived norms.

31. Graham J, Nosek BA, Haidt J, lyer R, Koleva S, Ditto PH. 2011 Mapping the moral domain. J. Pers. Soc. Psychol. 101, 366. (doi:10.1037/a0021847)

32. Körner A, Deutsch R, Gawronski B. 2020 Using the cni model to investigate individual differences in moral dilemma judgments. Pers. Soc. Psychol. Bull. 46, 1392-1407. (doi:10.1177/0146167220907203)

33. Cabrera LY, Fitz NS, Reiner PB. 2015 Empirical support for the moral salience of the therapyenhancement distinction in the debate over cognitive, affective and social enhancement Neuroethics 8, 243-256. (doi:10.1007/s12152-0149223-2)

34. Rini R. 2020 Deepfakes and the epistemic backstop. Phil. Imprint 20.

35. Pearce D. 1995 Hedonistic imperative. Selfpublished. Retrieved on 26-03-2021 from http:// happymutations.com/ebooks/david-pearce-thehedonistic-imperative.pdf.

36. Earp BD, Wudarczyk OA, Sandberg A, Savulescu J. 2013 If $i$ could just stop loving you: anti-love biotechnology and the ethics of a chemical breakup. Am. J. Bioethics 13, 3-17. (doi:10.1080/15265161. 2013.839752)

37. Goffette J 2006 Naissance de l'anthropotechnie: de la médecine au modelage de l'humain. Vrin.

38. Clarke AE, Shim JK, Mamo L, Fosket JR, Fishman JR. 2003 Biomedicalization: technoscientific transformations of health, illness, and us biomedicine. Am. Sociol. Rev. 161-194. (doi:10. 2307/1519765)

39. Davis D, Dooley M, Hook J, Choe E, McElroy-Heltzel S. 2016 The purity/sanctity subscale of the moral foundations questionnaire does not work similarly for religious versus non-religious individuals. Psychol. Religion and Spirituality 9, 124. (doi:10. 1037/rel0000057)

40. Kass L 2003 Beyond therapy: biotechnology and the pursuit of happiness. Executive Office of the President.

41. Persson I, Savulescu J. 2008 The perils of cognitive enhancement and the urgent imperative to enhance the moral character of humanity. J. Appl. Phil. 25, 162-177. (doi:10.1111/j.1468-5930.2008.00410.x)

42. Sahakian BJ, Morein-Zamir S. 2011 Neuroethical issues in cognitive enhancement. J. Psychopharmacol. 25, 197-204. (doi:10.1177/ 0269881109106926)

43. Kahane G. 2015 Sidetracked by trolleys: why sacrificial moral dilemmas tell us little (or nothing) about utilitarian judgment. Social Neurosci. 10, 551-560. (doi:10.1080/17470919.2015.1023400)

44. Schermer M 2015 Ethics of pharmacological mood enhancement. In Handbook of Neuroethics, pp. 1177-1190, New York NY: Springer

45. Kramer PD, Brody EB. 1994 Listening to prozac: a psychiatrist explores antidepressant drugs and the remaking of the self. J. Nervous Mental Dis. 182, 362. (doi:10.1097/00005053-199406000-(00017))

46. Michaud T 2020 Science fiction and innovation design. John Wiley \& Sons.

47. Greene JD, Sommerville RB, Nystrom LE, Darley JM, Cohen JD. 2001 An fmri investigation of emotional engagement in moral judgment. Science 293, 2105-2108. (doi:10.1126/science. 1062872)

48. Sidgwick H 1874 The methods of ethics. Macmillan and Company, limited; New York, NY: The Macmillan Company.

49. Trippett D. 2017 Music and the transhuman ear: ultrasonics, material bodies, and the limits of sensation. Musical Q. 100, 199-261. (doi:10.1093/ musqt//gdy001)

50. Kahane G. 2011 Reasons to feel, reasons to take pills. In Enhancing Human Capacities, pp. 166-178.

51. Ben-Ze'ev Aaron. 1997 Emotions and morality. J. Value Inquiry 31, 195-212. (doi:10.1023/ A:1004236823330)

52. Theriault JE, Young L, Barrett LF. 2021 The sense of should: a biologically-based framework for 
modeling social pressure. Phys. Life Rev. 36, 100-136. (doi:10.1016/j.plrev.2020.01.004)

53. Matsumoto D, Yoo SH, Fontaine J. 2008 Mapping expressive differences around the world: the relationship between emotional display rules and individualism versus collectivism. J. Cross-Cultural Psychol. 39, 55-74. (doi:10.1177/00220221 07311854)

54. European Space Agency. 2002 Innovative technologies from science fiction for space applications.

55. Thomas LB. 2014 Nanotech ideas in science fiction literature.

56. Michael K, Abbas R, Roussos G, Scornavacca E, Fosso-Wamba S. 2020 Dealing with technological trajectories: where we have come from and where we are going. IEEE Trans. Technol. Soc. 1, 2-7. (doi:10.1109/TTS.2020.2976425)

57. Haring KS, Mougenot C, Ono F, Watanabe K. 2014 Cultural differences in perception and attitude towards robots. Int. J. Affect. Eng. 13, 149-157. (doi:10.5057/ijae.13.149)

58. Henrich J, Heine SJ, Norenzayan A. 2010 Most people are not weird. Nature 466, 29-29. (doi:10. 1038/466029a)

59. Doğruyol B, Alper Sn, Yilmaz 0. 2019 The five-factor model of the moral foundations theory is stable across weird and non-weird cultures. Pers. Individual
Differences 151, 109547. (doi:10.1016/j.paid.2019. 109547)

60. Atari M, Graham J, Dehghani M. 2020 Foundations of morality in iran. Evol. Hum. Behav. 41, 367-384. (doi:10.1016/j.evolhumbehav.2020.07.014)

61. Berniūnas R. 2020 Mongolian yos surtakhuun and weird 'morality'. J. Cultural Cogn. Sci. 4, 59-71. (doi:10.1007/s41809-019-00045-1)

62. Awad E, Dsouza S, Shariff A, Rahwan I, Bonnefon J-F. 2020 Universals and variations in moral decisions made in 42 countries by 70,000 participants. Proc. Natl Acad. Sci. USA 117, 2332-2337. (doi:10.1073/pnas.1911517117)

63. Wu F, Ma Y, Zhang Z. 2021 'I found a more attractive deepfaked self: the self-enhancement effect in deepfake video exposure. Cyberpsychology, Behav. Soc. Netw. 24, 173-181. (doi:10.1089/cyber. 2020.0173)

64. Parkinson B, Manstead ASR. 1993 Making sense of emotion in stories and social life. Cogn. Emotion 7, 295-323. (doi:10.1080/0269993 9308409191)

65. Rey B, Simoncini N, Triclot M. 2021 Les sciences humaines et sociales en recherche technologique: vers une démarche de conception fondée sur l'ethnographie.

66. Tsakiris M. 2021 How should the political animals of the 21st century feel?: Comment on 'the sense of should: a biologically-based framework for modelling social pressure' by JE theriault et al. Phys. Life Rev. 36, 77-79. (doi:10.1016/j.plrev.2020.06. 008)

67. Khosravani S, Mahnan A, Yeh I-L, Aman JE, Watson PJ, Zhang Y, Goding G, Konczak J. 2019 Laryngeal vibration as a non-invasive neuromodulation therapy for spasmodic dysphonia. Sci. Rep. 9, 1-11. (doi:10.1038/s41598019-54396-4)

68. Aucouturier J-J, Johansson P, Hall L, Segnini R, Mercadié L, Watanabe K. 2016 Covert digital manipulation of vocal emotion alter speakers' emotional states in a congruent direction. Proc. Natl Acad. Sci. USA 113, 948-953. (doi:10.1073/pnas. 1506552113)

69. Métayer S, Pahlavan F. 2014 Validation of the moral foundations questionnaire in French. Revue Int. de Psychologie Sociale 27, 79-107.

70. Curry OS, Chesters MJ, Van Lissa CJ. 2019 Mapping morality with a compass: testing the theory of 'morality-as-cooperation' with a new questionnaire. J. Res. Personal. 78, 106-124. (doi:10.1016/j.jp. 2018.10.008)

71. Zakharin M, Bates T. 2021 Remapping the foundations of morality: well-fitting structural model of the moral foundations questionnaire. 